\title{
A BIOGRAFIA NA HISTÓRIA DA ARTE: O "CONFRONTO" ENTRE ANITA E TARSILA
}

\author{
Prof. Dra. Maria de Fátima Morethy Couto ${ }^{1}$
}

\section{Resumo:}

Minha comunicação tem por objetivo analisar um aspecto preciso da historiografia de dois ícones do movimento modernista brasileiro: o "confronto" que teria existido entre a bela Tarsila e a "mulher-menina" Anita Malfatti. Para alguns historiadores, o mal-estar criado pela convivência com Tarsila foi uma das razões que levaram Anita a recuar de seu engajamento vanguardista e buscar uma arte "sem excessos". Destaco aqui a contribuição de dois autores: Gilda de Mello e Souza, em seu artigo "Vanguarda e Nacionalismo na década de Vinte", de 1975, e Sérgio Miceli, em seu livro Nacional Estrangeiro, publicado em 2003, tratam do tema apontando o quanto as vantagens físicas e materiais de Tarsila ajudaram-na a impor-se como a musa final do movimento modernista brasileiro.

Palavras-chave: modernismo brasileiro, biografia, história da arte

O movimento modernista brasileiro foi marcado pelo trabalho de duas mulheres de origem e temperamento bastante distintos: Anita Malfatti e Tarsila do Amaral. Enquanto a primeira é considerada "o estopim do modernismo" no país, devido ao escândalo causado no acanhado meio paulistano por sua exposição individual de 1917 e pela célebre polêmica com Monteiro Lobato, a segunda é tida como a grande musa do movimento, em razão de suas telas da fase Pau Brasil e Antropofágica, que tão bem ilustraram o pensamento moderno em eclosão naquele momento. Entretanto, quando da realização da Semana de Arte Moderna de 1922, Tarsila ainda pintava nos moldes acadêmicos, ao passo que Anita, embora já hesitante quanto aos rumos de seu trabalho, afirmava-se como um dos grandes nomes do evento.

No ano seguinte, ambas encontram-se na Europa em viagem de "estudos". Tarsila, financiada pela família, demonstra-se decidida dar uma guinada em sua carreira, abandonando os antigos conselhos de Pedro Alexandrino e adotando preceitos da vanguarda cubista. Estuda com Lothe, Léger e Gleizes e pinta quadros que revelam sua nova orientação estética, como Caipirinha e A Negra ou seu famoso Auto-retrato com casaco vermelho. Envolve-se com Oswald de Andrade, com quem mantém uma parceria bastante profícua também no trabalho. Volta ao Brasil em 1924 e recebe fortes elogios de Mário de Andrade, que se mostra entusiasmado com sua nova produção. "Quem me surpreendeu inteiramente foi Tarsila. Que progresso, para tão pouco tempo! (...) Estou entusiasmado", escreve ele a Anita. "Aquela Tarsila curiosa de coisas novas, mas indecisa, insapiente que eu conhecera, desapareceu. Encontrei uma instrução desenvolvida, arregimentada e rica. Vê-se que muito ouviu, muito leu e muito pensou". ${ }^{2}$ No ano seguinte, os elogios se repetem:

Tarsila está um bicho. Tem feito coisas colossais, tentando a criação duma arte brasileira mas brasileira de verdade. Certas paisagens das últimas e uns quadros aproveitandos tipos e santos nacionais são das milhores pinturas modernas que

\footnotetext{
${ }^{1}$ Instituto de Artes/Unicamp, mfmcouto@iar.unicamp.br

2 Marta Rossetti Batista, org., Mário de Andrade. Cartas a Anita Malfatti (1921-1939), São Paulo, Forense Universitária, 1989, p. 66. Carta datada de 3 de janeiro de 1924.
} 
conheço. Junto a um dinamismo e sobretudo uma firmeza de linha e um equilíbrio perfeitos, um gosto forte de coisa bem brasileira com cheiro de manacá e abacaxi, melando a alma da gente. Acho que ela achou com felicidade rara o caminho que devia seguir. ${ }^{3}$

Já Anita, bolsista do Pensionato Artístico do Estado de São Paulo graças à interferência do amigo Mário de Andrade junto a Freitas Valle, dava início a um processo de revisão de seu engajamento expressionista, ou de significativo retrocesso no plano formal, se pensarmos em termos vanguardistas. Em sua nova estada de cinco anos na Europa, interessa-se pelos pintores da chamada Escola de Paris e estuda com Maurice Denis. Assume uma postura mais comedida em seu trabalho, buscando uma arte moderna "sem excessos" $\mathrm{e}$ "sem a violência dos períodos heróicos", realizando interiores de tons intimistas e contornos delicados, que lembram os quadros de Bonnard e Vuillard e paisagens de fatura equilibrada, construídas por planos sucessivos. Tem sua obra aceita em alguns Salões parisienses, como as edições de 1924 e 1927 do Salão de Outono e o Salão dos Independentes de 1926, mas desaponta os amigos brasileiros, que ansiavam por experimentações mais ousadas na trilha do expressionismo dos quadros de 1915/1917. Em carta a Mário, enviada no início de 1925, Anita se queixa de seu isolamento em Paris, ao que ele responde:

Os meus amigos me conhecem bem e nunca me falaram mal de você ou de suas obras, porém eu senti que se estavam desinteressando por você. Senti e sofri. Acho que eles procedem mal (...) porque si você mudou de orientação, si você não tem a opinião mesminha deles, isso não é razão para que se afastem. (...) Se um dia eles reconheceram que você tinha talento, deviam esperar pra ver o que você ia fazer no novo caminho. ${ }^{4}$

O próprio Mário, porém, decepciona-se com a "variedade estética desnorteante" dos trabalhos de Anita apresentados em sua primeira exposição individual após seu retorno ao país, realizada em 1929 e escreve sobre a participação da amiga no Salão Nacional de Belas Artes de 1931, conhecido como "Salão Revolucionário: "O que Anita faz de novo me inquieta". 5 inquietação transformou-se em seguida em "franca desaprovação" dos rumos tomados pela pintora, conforme salienta Marta Rosetti Batista. ${ }^{6}$

Anita, contudo, parece não ter dúvida do ocaso das vanguardas européias. Em depoimento publicado logo de sua chegada ao Brasil, ela indica que sua opção por uma arte menos "revolucionária" foi consciente, ao afirmar, por exemplo:

Em Paris, no ano em que lá cheguei, 1923, encontrei o ambiente que é o mesmo, quase, dos dias de hoje: um movimento generalizado dos artistas, norteados

${ }^{3}$ Idem, pp. 103-104. Carta datada de 4 de dezembro de 1925.

${ }^{4}$ Idem, pp. 97-98. Carta datada de 19 de março de 1925. A Sérgio Milliet, porém, Mário escrevera em 11 de agosto de 1924: "E Anita? O que todos vocês me dizem sobre ela me horroriza".

${ }^{5}$ Idem, p. 35.

${ }^{6}$ Quando Anita escreve-lhe, ao final dos anos 1930, que deseja fazer uma arte "com sabor de Debret e Rugendas", Mário responde: "Você argumenta, por exemplo, que eu também posso fazer uma elegia à maneira de Camões e um soneto parnasiano no estilo de Bilac. Posso, não tem dúvida. Mas quando os fizer, farei por brinquedo ou por exercício de estilo, convencido de que se trata de um a la manière de... e nunca de uma verdade funcional da minha personalidade artística. Quando quero fazer arte, mas arte de verdade, arte vertical, só posso fazer arte minha, sem buscar estilos ou feitos alheios ou do passado, a minha função. Que esta só pode ser minha e, por ser minha, é do meu tempo". Apud Marta Batista Rossetti, Anita Malfatti no tempo e no espaço, São Paulo, IBM, 1986, p. 136. 
definitivamente por tendências modernistas. Há a notar, entretanto, um pormenor que não pode passar despercebido: os extremistas não têm mais lugar de destaque. As tendências modernas a que me referi representam correntes moderadas, sem, contudo, deixar de ser caracteristicamente novas. ${ }^{7}$

Muito do que falei acima é de conhecimento de todos. Estudos basilares sobre as duas artistas já foram publicados, trazendo a público amplo material sobre o desenvolvimento de suas carreiras. ${ }^{8}$ Pretendo aqui discutir a intepretação dada por alguns historiadores ao retraimento estético-formal de Anita, entendendo-o como um problema de insegurança pessoal, acentuado pela entrada em cena da bela e aristocrática Tarsila, a qual logo se transformaria na "musa do modernismo" e atuaria como intermediária entre colecionadores brasileiros e vanguarda parisiense.

Gilda de Mello e Souza, em texto primoroso sobre o movimento modernista, datado de 1975 , foi talvez uma das primeiras a apontar para esse "confronto" entre duas mulheres de "trunfos tão desiguais", 10 ressaltando o quanto deve ter sido difícil para "a moça feia e sem afeto amoroso" que foi Anita o convívio diário com a beleza e segurança de Tarsila. Segundo a autora, até aquele momento, a historiografia sobre o modernismo brasileiro canalizara para o artigo "tristemente célebre de Monteiro Lobato toda a responsabilidade do incesso posterior da pintora [Anita]". A seu ver, os fatos foram mais complexos e deveriam ser revistos. Naquele momento de luta, afirma Gilda, Anita não se sentiu sozinha pois teve o apoio dos "ainda embrionários modenistas". Mais sérias, acredita, foram as outras provas, que a artista precisou enfrentar só. A primeira, assinala, foi o "evidente desacordo entre o seu temperamento e o nacionalismo, a que haviam aderido os companheiros". Que sentido, pergunta Gilda, "poderia ter isso para o seu temperamento fechado e solitário, que só contava com a arte para se exprimir? Como conter num programa estrito e definido a sua alma ferida, esquiva e no entanto sequiosa de comunicação?"11 A segunda prova, alerta a autora, foi a "dificuldade mais sofrida, porque Anita não a pôde confessar nem a si mesma":

Até agora ninguém a mencionou, porque, como os demais setores da cultura, a crítica reflete a visão masculina e estabelece de antemão a importância dos motivos esquecendo na sombra os que reputa insignificantes. No entanto, não é difícil avaliar o que terá sido para Anita o confronto diário com a beleza de Tarsila. É falso racionalizar, dizendo que era uma artista de prestígio e lhe bastava a admiração que os modernistas votavam à sua arte. Acaso manifestavam a Tarsila um interesse estritamente artístico? Não a consideravam também, além de excelente pintora, a "maravilha caída do céu", a "caipirinha vestida de Poiret", "deusa", "senhora do

7 Apud Idem, p. 106.

8 Ver, sobre Anita, o livro citado acima e Aracy Amaral, Tarsila: sua obra seu tempo, São Paulo, Edusp e Ed. 34, 2003 (primeira edição 1975). Ressalto ainda a importância da publicação da correspondência de Mário de Andrade com ambas as artistas, para um melhor entendimento dos passos, descobertas e recuos dados por Anita e Tarsila e das expectativas do crítico de arte.

9 Trata-se de "Vanguarda e Nacionalismo na década de Vinte", originalmente escrito para figurar no catálogo da exposição O modernismo - pintura brasileira contemporânea de 1917 a 1930, realizada no Museu Lasar Segall. O texto foi reproduzido na coletânea O Baile das Quatro Artes. Exercicios de Leitura, São Paulo, Livraria Duas Cidades, 1980, pp. 249-277, versão na qual me baseio para as citações.

10 A expressão é de Sérgio Miceli, em livro que analisaremos em seguida.

11 Gilda de Mello e Souza, "Vanguarda e Nacionalismo na década de Vinte", op. cit., p. 271. 
equilíbrio e da medida, inimiga dos excessos"? 12

Gilda de Mello e Souza considera Tarsila uma "pintora de enorme talento, mas nem muito profunda nem excepcionalmente original". Em sua opinião, Tarsila "tem algo da mentalidade de aluna; brilhante disciplinada, cumpridora de tarefas, imaginosa, mas que só inventa sobre um esquema preexistente. A sua sorte", afirma, "foi encontrar no caminho as normas de uma estética precisa e as linhas gerais de uma visão do mundo, às quais se acomodou com a docilidade de intérprete, de executante". Entretanto, Gilda não deixa de assinalar outro fator de revelo para seu desempenho estético: "o fato de ter sido uma mulher bonita (...) colaborou na expansão harmoniosa de sua personalidade. Se isto jamais interferiu diretamente na avaliação que os contemporâneos fizeram do seu talento, auxilou-a sem dúvida a cumprir seu destino". ${ }^{13}$ Quanto à Anita, "seu comportamento [em termos de retrocesso artístico] é de quem foi rejeitada: pela vida, que não a fez bonita; pela crítica, que investiu contra sua arte; pela estética vigente, que não lhe permitiu extravasar o drama pessoal; pelos companheiros, que não a trataram como mulher". ${ }^{14}$

Em Nacional Estrangeiro, livro no qual analisa a rede de relações entre artistas modernistas e mecenato paulista, lançado em 2003, Sérgio Miceli retoma a idéia desenvolvida anteriormente por Gilda de Mello e Souza, salientando a necessidade sentida por Tarsila, nos idos de 1923, de "fazer frente à dianteira técnico-estética da concorrente Anita Malfatti":

A Tarsila que retorna à Europa em 1923, em companhia da filha adolescente, apaixonada por Oswald, é uma mulher atraente, sofisticada, repaginada com toaletes de alta-costura, decidida a alterar os rumos de seu aprendizado artístico, dando agora preferência a mestres ligados às vanguardas. (...) Tarsila, a desafiante, tanto em matéria artística como em termos de sedução pessoal, com a beleza esfuziante nos seus 36 anos, originária de riquíssima família da artistocracia rural (...), estava decidida a mobilizar o que fosse preciso para afirmar sua condição de mulher e artista bemsucedida. ${ }^{15}$

Já Anita, "a profissional mais experiente e mais jovem, (...) possuía nas mãos o instrumento de sua redenção pessoal, social e o estigma responsável pelo bloqueio de uma vida amorosa". ${ }^{16}$ Miceli refere-se aqui ao defeito congênito na mão direita da artista, defeito esse insistentemente mencionado por todos os estudiosos de sua obra, os quais chegam a relacionálo ao fato de vários retratos da fase "revolucionária" - e mais original - da artista apresentarem mãos cortadas e/ou parcialmente escondidadas. A mão deformada, sempre recoberta por um "lenço colorido displicentemente ali esquecido", transforma-se então em uma "fragilidade física", que, por sua vez, resultou em uma "fragilidade emocional", também recorrentemente citada. Para Miceli, tal fragilidade físico-emocional determinou a escolha profissional de Anita, assim como os rumos de seu trabalho, impedindo-a de criar um percurso uniforme e sem vacilações:

12 Idem, pp. 271-272.

13 Idem, p. 269.

${ }^{14}$ Idem, p. 272.

15 Sérgio Miceli, Nacional Estrangeiro, São Paulo, Companhia das Letras, 2003, em especial os capítulos “Anita Malfatti: gênero e experiência imigrante" e "Tarsila do Amaral: a substituição de importações estéticas". A citação encontra-se nas páginas 115 e 130.

16 Idem, p. 115. 
Talvez as mesmas raízes e motivações que instigaram sua vontade de ser artista foram também responsáveis pela crise de identidade profissional que a fez retroagir em sua prática artística. A marca autoral de Anita tem a ver, sobretudo, com suas dificuldades de assumir sua plenitude afetiva como mulher, em parte por conta de suas constrições de imigrante, que a condenam ao celibato, em parte por força da postura defensiva que se viu impelida a adotar em virtude da mão defeituosa. ${ }^{17}$

Para o autor, o confronto entre as artistas citadas estabeleceu-se, portanto, em bases bastante desiguais e sua "vencedora" não poderia ser outra:

Enquanto a estigmatizada Anita Malfatti constrói sua obra como protocolo sofrido de um itinerário afetivo marcado pela solidão e pelo isolamento, acossada por carências físicas e afetivas (a mão defeituosa, o celibato), a belíssima Tarsila do Amaral desenvolve o período de maior criatividade de sua carreira como artista plástica nos ritmos e conteúdos ditados pela parceria amorosa com o escritor Oswald de Andrade. ${ }^{18}$

Miceli entende que "o fato de algumas das mais importantes figuras do modernismo artístico brasileiro terem sido mulheres tornou as vivências ligadas à identidade sexual e de gênero um dos eixos temáticos e conceituais das formalizações expressivas da prática artística naquela geração". ${ }^{19}$ Mas estaríamos nós, mulheres, fadadas, por questões de gênero, a rivalidades em tais termos e a misturar o campo pessoal com o profissional de forma tão emotiva? Ou ainda, poderíamos utilizar esses mesmos parâmetros de análise para estudar a obra de pintores representativos de nosso movimento modernista? Estabelecer, por exemplo, um confronto entre o "filho e neto de modestos imigrantes italianos recém-instalados no interior paulista, coxo e de pequena estatura" ${ }^{20}$ Portinari e o exuberante e boêmio Di Cavalcanti que explicasse suas idas e vindas no campo artístico?

Não se trata aqui de negar o encantamento de Mário, para não citar Oswald, em relação à Tarsila. Em suas cartas endereçadas à artista, Mário refere-se a ela como "Tarsila boniteza", ou mesmo como a deusa greco-romana Nêmesis, que cuidava da boa sorte na vida humana e que aplicava castigos devido a más ações, para logo se "corrigir": "Que és deusa, tenho certeza disso: pelo teu porte, pela tua inteligência, pela tua beleza. Mas a deusa que reprime o excesso dos prazeres? Não creio. Tua recordação só me inunda de alegria e suavidade", escreve em 1923, em um tom jamais empregado nas cartas que escreve para Anita. ${ }^{21}$ Entretanto, cabe ressaltar que esta "sensitiva exaltada, mixto de adulto e de criança, independência e medo"22 que foi Anita soube reagir com veemência e segurança às investidas de sua "consciênciacrítica", seu amigo Mário de Andrade, quando este, em suas cartas, procurava orientá-la em seus passos em Paris. Anita também posicionou-se criticamente em relação à exposição

${ }^{17}$ Idem, p. 123.

${ }^{18}$ Idem, p. 97. Miceli refere-se ainda em seu texto ao amor platônico de Anita em relação a seu amigo Mário, e analisa alguns de seus quadros dentro desse prisma.

${ }^{19}$ Idem, p. 102.

20 Sérgio Miceli assim se refere a Portinari em seu livro Imagens Negociadas Retratos da elite brasileira (1920-1940), São Paulo, Cia das Letras, 1996

21 Aracy Amaral, org, Correspondência Mário de Andrade \& Tarsila do Amaral, São Paulo, Edusp/IEB, 1999, pp. 5758. Carta datada de 11 de janeiro de 2003.

22 As expressões são de autoria de Marta Rossetti Batista. 
individual de Tarsila na galeria Percier, em junho de 1926, em Paris. ${ }^{23}$

Certamente não sou a primeira a levantar tais objeções em relação à historiografia vigente sobre Anita Malfatti. Tadeu Chiarelli talvez tenha sido um dos primeiros a tentar desmistificar a "fraqueza de Anita" como causa de seu "retrocesso". Pare ele, Anita sofreu do descaso que a história da arte oficial do século XX tratou "os artistas que, apenas circunstancialmente, tangenciaram o projeto moderno no decorrer de suas trajetórias e/ou que se engajaram por breve período nas correntes que contestavam tanto a tradição quanto a própria modernidade". ${ }^{24}$ Em sua resenha sobre o livro de Marta Rossetti Batista dedicado a Anita, Chiarelli elogia a tentativa da autora de "entender de fato o recuo da artista em relação aos postulados das vanguardas do início do século, em vez de julgar os passo posteriores de Malfatti, baseada em critérios da crítica moderna" e alerta para a necessidade de vermos "Anita Malfatti como protagonista de sua própria vida, optando conscientemente pelos rumos de sua trajetória artística, (...) e não como uma sensitiva influenciável, sem vontade própria, incapaz de arbritar sobre os caminhos de sua arte". 25 Para finalizar, resta-me afirmar que dados biográficos podem auxiliar o historiador em sua análise do desenvolvimento de uma obra mas este deve estar sempre consciente do perigo de sucumbir a tramas mirabolantes e sedutoras, justificáveis, no caso em questão, apenas quando inseridas na rubrica de "questões de gênero".

${ }^{23}$ Conforme carta de Mário a Anita, datada de 24 de julho de 1926.

24 Tadeu Chiarelli, "Anita Malfatti no tempo e no espaço". In Arte internacional brasileira, São Paulo, Lemos editorial, 1999, p. 158. Ver também do mesmo autor Um jeca nos vernissages, São Paulo, Edusp, 1995.

${ }^{25}$ Idem, p. 162. 